\title{
MATURIDADE SEXUAL DE POTIMIRIM BRASILIANA (CARIDEA, ATYIDAE) DE UM RIACHO NA REGIÃO DE UBATUBA, SÃO PAULO, BRASIL
}

\author{
Galiotti, L.L., ${ }^{1,}$; Machado, M.C. ${ }^{1}$; Gonçalves, G.L. '; Hoffmann, P. ${ }^{2}$ \& Negreiros-Fransozo, M.L. ${ }^{1}$ \\ ${ }^{1}$ Núcleo de Estudos em Biologia, Ecologia e Cultivo de Crustáceos, NEBECC, Departamento de Zoologia, Instituto \\ de Biociências, UNESP, Botucatu, São Paulo, Brasil. \\ 2 Universidade Paulista, UNIP, São José do Rio Preto, São Paulo, Brasil. \\ *Autor correspondente: lucasgaliotti.bio@gmail.com
}

\begin{abstract}
Os aspectos biológicos dos camarões carídeos são pouco conhecidos, particularmente, quando as espécies não apresentam interesse econômico, como é o caso de Potimirim brasiliana Villalobos, 1959. Desse modo, estudouse a maturidade sexual morfológica de uma população de $P$. brasiliana, proveniente de um riacho do Bairro de Camburi, Ubatuba, São Paulo, Brasil. Os camarões foram amostrados, mensalmente, de março de 2005 a fevereiro de 2006, utilizando-se peneiras manuais, junto às rochas. Analisou-se o comprimento da carapaça (CC), comprimento da segunda pleura (CP), comprimento (CASM) e largura (LASM) do apêndice sexual masculino, por meio do crescimento relativo destas dimensões. Foram coletados 6977 espécimes; dos quais, somente parte deles foi analisada, ou seja, 539 eram fêmeas (481 ovígeras) e 1190 machos. Todas as relações testadas entre os grupos do mesmo sexo diferiram entre si (ANCOVA; $p=0,00)$. Entre as relações testadas, aquelas que melhor refletiram o crescimento relativo da espécie foram CC vs. CP, CC vs. CASM e CC vs. LASM. A maturidade sexual morfológica das fêmeas $\left(\mathrm{CC}_{50 \%}\right.$ ) obtida foi $2,29 \mathrm{~mm}$; a qual é menor do que o valor da menor fêmea ovígera (3,2 mm CC). Os machos foram separados em três morfotipos, sendo um para jovens e dois para adultos (Morf. I e Morf. II). A relação CC vs. CASM representa melhor as separações entre morfotipos e maturidade sexual. A maturidade sexual $\left(\mathrm{CC}_{50 \%}\right)$ encontrada para os machos foi 2,73 mm de CC. Os resultados mostram que as fêmeas atingem a maturidade sexual em tamanhos numéricos menores que os machos, cuja diferença é de $0,44 \mathrm{~mm}$. Apesar de estes camarões serem bem pequenos (comparado com outros carídeos), tal diferença é muito pequena para se considerar que a maturidade, entre os sexos, seja diferente do ponto de vista biológico. Por outro lado, a literatura aponta que, entre os camarões de água doce, é comum que os machos atinjam maiores dimensões, provavelmente, assegurando a cópula e garantindo a competição intraespecífica. O aparecimento de machos com morfotipos é uma questão intrigante, pois se observa que camarões com tamanhos similares (Morf. I = $3.36 \pm 0,29 \mathrm{~mm}$; Morf. II = $3.46 \pm 0,26 \mathrm{~mm}$ ) podem apresentar o comprimento do apêndice sexual masculino distinto (Morf. I=3,76 \pm 0,55mm; Morf. II $5.56 \pm 0,65 \mathrm{~mm}$ ). Aparentemente, os morfotipos possuem funções distintas na reprodução; contudo somente estudos comportamentais detalhados poderão esclarecer tal função.
\end{abstract}

Palavras-chave: camarão miúdo, reprodução, morfologia, Caridea, Ubatuba. 